\title{
Journal of Developmental Biology
}

an Open Access Journal by MDPI

Indexed in:

CITESCORE

PubMed $\quad 3.6$ 


\section{Journal of}

Developmental Biology

an Open Access Journal by MDPI

Editor-in-Chief

Prof. Dr. Simon J. Conway

\section{Message from the Editor-in-Chief}

The Journal of Developmental Biology (JDB) publishes original research papers and timely reviews. Our primary aim is to provide a platform for publication of studies on the development of multicellular organisms efficiently and professionally; papers undergo a fast, yet thorough, peer-review process. JDB is an open access journal and accepted contributions are published immediately online, providing unlimited access to the scientific community and general public. We look forward to receiving your contribution to our journal and to working with fellow researchers.

\section{Author Benefits}

O Open Access Unlimited and free access for readers

C No Copyright Constraints Retain copyright of your work and free use of your article

\section{\& Thorough Peer-Review}

S Discounts on Article Processing Charges (APC) If you belong to an institute that participates with the MDPI Institutional Open Access Program (IOAP)

【 No Space Constraints, No Extra Space or Color Charges No restriction on the length of the papers, number of figures or colors

Coverage by Leading Indexing Services Scopus, ESCI (Web of Science), PubMed, PMC, PubAg, CAPlus / SciFinder, and many other databases

¿ Rapid Publication Manuscripts are peer-reviewed and a first decision provided to authors approximately 16 days after submission; acceptance to publication is undertaken in 4 days 


\section{Aims and Scope}

Journal of Developmental Biology (ISSN 2221-3759) is an international, peer-reviewed, quick-refereeing, open access journal, which publishes reviews, research papers and communications on the development of multicellular organisms at the molecule, cell, tissue, organ and whole organism levels. Our aim is to encourage researchers to effortlessly publish their new findings or concepts rapidly in an open access medium overseen by their peers. There is no restriction on the length of the papers; the full experimental details must be provided so that results can be reproduced.

The scope of JDB includes:

Embryonic and fetal development

Molecular regulation of development

Cell differentiation and lineage specification

Organogenesis

Animal models of inherited and acquired birth defects

Tissue regeneration

Developmental origins of disease

\section{Editorial Office}

JDB Editorial Office jdb@mdpi.com MDPI, St. Alban-Anlage 66 4052 Basel, Switzerland Tel: +41616837734 www.mdpi.com mdpi.com/journal/jdb 


\section{MDPI is a member of}

\section{CASPA}

The Association of Learned \& Profession

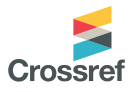

¿STM'

Society

for Scholarly

Publishing
$|\mathbf{C}| \mathbf{O}|\mathbf{P}| \mathbf{E}$

SPARC*

Europe

\section{DOAJ}

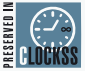

ORCID

\section{Follow Us}

f facebook.com/MDPIOpenAccessPublishing

twitter.com/MDPIOpenAccess

in linkedin.com/company/mdpi

$\boldsymbol{6}^{\text {") }}$ weibo.com/mdpicn

(1) Wechat:MDPI-China

(14) blog.mdpi.com

See www.mdpi.com for a full list of offices and contact information. MDPI is a company registered in Basel, Switzerland, No. CH-270.3.014.334-3, whose registered office is at St. Alban-Anlage 66, CH-4052 Basel, Switzerland. 